\title{
A Bayesian decision approach to rainfall thresholds based flood warning
}

\author{
M. L. V. Martina, E. Todini, and A. Libralon \\ Dept. of Earth and Geo-Environmental Sciences, Univ. of Bologna, Piazza di Porta San Donato, 1, Bologna, 40126, Italy
}

Received: 13 October 2005 - Published in Hydrol. Earth Syst. Sci. Discuss.: 13 December 2005

Revised: 31 March 2006 - Accepted: 1 April 2006 - Published: 7 June 2006

\begin{abstract}
Operational real time flood forecasting systems generally require a hydrological model to run in real time as well as a series of hydro-informatics tools to transform the flood forecast into relatively simple and clear messages to the decision makers involved in flood defense. The scope of this paper is to set forth the possibility of providing flood warnings at given river sections based on the direct comparison of the quantitative precipitation forecast with critical rainfall threshold values, without the need of an on-line real time forecasting system. This approach leads to an extremely simplified alert system to be used by non technical stakeholders and could also be used to supplement the traditional flood forecasting systems in case of system failures. The critical rainfall threshold values, incorporating the soil moisture initial conditions, result from statistical analyses using long hydrological time series combined with a Bayesian utility function minimization. In the paper, results of an application of the proposed methodology to the Sieve river, a tributary of the Arno river in Italy, are given to exemplify its practical applicability.
\end{abstract}

\section{Introduction}

\subsection{The flood warning problem}

The aim of any flood warning system is to provide useful information to improving decisions such as for instance issuing alerts or activating the required protection measures. Traditional flood warning systems are based on on-line hydrological and/or hydraulic models capable of providing forecasts of discharges and/or water stages at critical river sections. Recently, flood warning systems have also been coupled with quantitative precipitation forecasts (QPF) gener- ated by numerical weather models (NWM), in order to extend the forecasting horizon from a few hours to a few days (EFFS, 2001-2004). Consequently, flood forecasting systems tend to require hydrological/hydraulic models to run in real time during flood emergencies, with increasing possibility of system failures due to several unexpected causes such as model instabilities, wrong updating procedures, error propagation, etc.

In several countries operational flood management rests with professional who have the appropriate technical background to interpret all of the information provided by the real-time flood forecasting chain. However, in many other cases, the responsibility of issuing warnings or to take emergency decisions rests with non hydro-meteorology knowledgeable stakeholders, this is the case for instance of flood emergency managers or mayors.

The aim of this paper is to explore the possibility of issuing flood warnings by directly comparing the forecast QPF to a critical rainfall threshold value incorporating all the important aspects of the problem (initial soil moisture conditions as well as expected costs), without the need to run the full chain of meteorological and hydrological/hydraulic real time forecasting models. Although it should not be considered as an alternative to the comprehensive hydro-meteorological forecasting chain, due to the simplicity of the final product (a couple of graphs), this approach can be an immediate tool for non purely technical decision makers in the case of early warnings and flash floods.

Apart from their extensive use in the United States (Georgakakos, 2006) and in Central America, in Europe, the Integrated Project FLOODSite (http://www.floodsite.net) among others aims at assessing the advantage for using the rainfall threshold approach as an alternative to the traditional ones in the case of flash floods.

Correspondence to: M. L. V. Martina

(martina@geomin.unibo.it)

Published by Copernicus GmbH on behalf of the European Geosciences Union. 


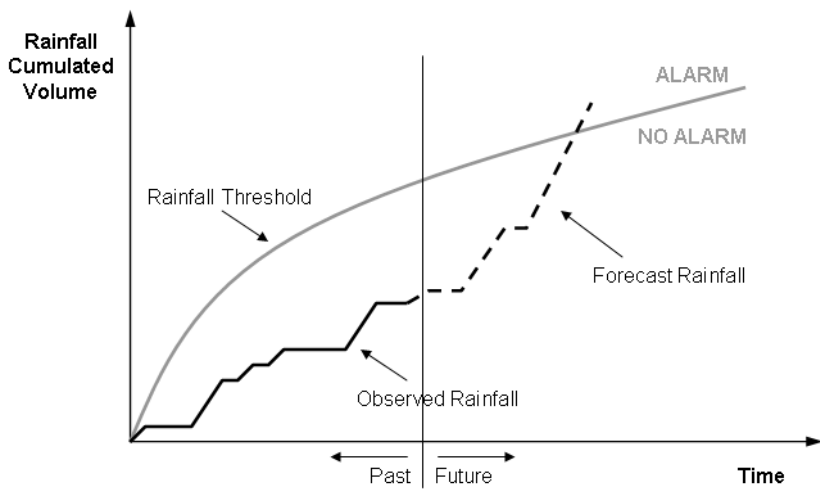

Fig. 1. Example of a rainfall threshold and its use.

\subsection{The rainfall threshold approach}

The use of rainfall thresholds is common in the context of landslides and debris flow hazard forecasting (Neary et al., 1986; Annunziati et al., 1996; Crosta and Frattini, 2000). Rainfall intensity increases surface landslide hazard (Crosta and Frattini, 2003) while soil moisture content affects slope stability (Iverson, 2000; Hennrich, 2000; Crosta et Frattini, 2001).

In the context of flood forecasting/warning, rainfall thresholds have been generally used by meteorological organizations or by the Civil Protection Agencies to issue alerts. For instance, in Italy an alert is issued by the Civil Protection Agency if a storm event of more than $50 \mathrm{~mm}$ is forecast for the next $24 \mathrm{~h}$ over an area ranging from 2 to $50 \mathrm{~km}^{2}$. Unfortunately, this type of rainfall threshold, which does not account for the actual soil saturation conditions at the onset of a storm event, tends to heavily increase the number of false alarms.

In order to analyze flood warning rainfall thresholds in more detail, following the definition of thresholds used for landslides hazard forecast, let us define them as "the cumulated volume of rainfall during a storm event which can generate a critical water stage (or discharge) at a specific river section". Figure 1 shows an example of rainfall thresholds i.e. accumulated volume of rain versus time of rainfall accumulation. In order to establish the landslides warning thresholds, De Vita and Reichenbach (1998) use a number of statistics (such as the mean), to be derived from long historical records, of the amount of precipitation that happened immediately before the event.

Mancini et al. (2002), as an alternative to the use of historical records in the case of floods, proposed an approach based on synthetic hyetographs with different shapes and durations for the estimation of flood warning rainfall thresholds. The threshold values are estimated by trial and error with an event based rainfall-runoff model, as the value of rainfall producing a critical discharge or critical water stage. Although the Mancini et al. (2002) approach overcomes the limitations of the statistical analysis based exclusively on historical records, rarely sufficiently long to produce statistically meaningful results, it presents some drawbacks due to the use of an event based hydrological model. In particular, it requires assumptions both on the temporal evolution of the designed storms and on the antecedent moisture conditions of the catchment, which one would like to avoid.

A rainfall threshold approach has also been developed and used within the U.S. National Weather Service (NWS) flash flood watch/warning programme (Carpenter et al., 1999). Flash flood warnings and watches are issued by local NWS Weather Forecast Offices (WFOs), based on the comparison of flash flood guidance (FFG) values with rainfall amounts. FFG refers generally to the volume of rain of a given duration necessary to cause minor flooding on small streams. Guidance values are determined by regional River Forecast Centers (RFCs) and provided to local WFOs for flood forecasting and the issuance of flash flood watches and warnings. The basis of FFG is the computation of threshold runoff values, or the amount of effective rainfall of a given duration that is necessary to cause minor flooding. Effective rainfall is the residual rainfall after losses due to infiltration, detention, and evaporation have been subtracted from the actual rainfall: it is the portion of rainfall that becomes surface runoff at the catchment scale. The determination of FFG value in an operational context requires the development of (i) estimates of threshold runoff volume for various rainfall durations, and (ii) a relationship between rainfall and runoff as a function of the soil moisture conditions to be estimated for instance via a soil moisture accounting model (Sweeney et a., 1992).

As applied in the USA, approaches for determining threshold runoff estimates varied from one RFC to another, and in many cases, were not based on generally applicable, objective methods. Carpenter et al. (1999) developed a procedure to provide improved estimates of threshold runoff based on objective hydrologic principles. For any specific duration, the runoff thresholds are computed as the flow causing flooding divided by the catchment area times the Unit Hydrograph peak value. The procedure includes four methods of computing threshold runoff according to the definition of flooding flow (two-year return period flow or bankfull discharge) and the methodology to estimate of the Unit Hydrograph peak (Synder's synthetic Unit Hydrograph or Geomorphologic Unit Hydrograph). A Geographic Information System is used to process digital terrain data and to compute catchment-scale characteristics (such as drainage area, stream length and average channel slope), while regional relationships are used to estimate channel cross-sectional and flow parameters from the catchment-scale characteristics in the different locations within the region of application. However the quality of the regional relationships, along with the assumptions of the theory, limits the applicability of the approach. For example, the assumption that the catchment responds linearly to rainfall excess, which is needed to apply the unit hydrograph theory, imposes lower limits on the size of the catchment, as small catchments are more non-linear 
than larger ones (Wang et al., 1981). But at the same time, the assumption of uniform rainfall excess over the whole catchment implicitly introduces upper bounds on the size of the catchments where a Unit Hydrograph approach could be considered reasonable. Furthermore, the assumption of uniform rainfall excess over the catchment also implicitly limits the size of the catchment for which a unit hydrograph approach is reasonable.

With reference to the second aspect of the FFG, namely the estimation of the relationship between rainfall and runoff as a function of the soil moisture conditions, in a recent paper Georgakakos (2005) derives a relationship between actual rainfall and runoff, which is taken equal to the effective rainfall, both for the operational Sacramento soil moisture accounting (SAC) model and for a simpler general saturationexcess model.

The results of this work have significant implications in operational application of the methodology. The threshold runoff is a function of the watershed surface geomorphologic characteristics and channel geometry but it also depends on the duration of the effective rainfall. This dependence implies one more relationship that must be invoked to determine the appropriate value and duration of the threshold runoff for any given initial soil moisture conditions. In other words operationally it is necessary to determine not only the relationship between the runoff thresholds and the flash flood guidance in terms of volumes but also in terms of their respective duration.

The method presented in this paper overcomes all the limitations due to historical records length, and the restrictive linearity assumptions required by the Unit Hydrograph approach as well as the ones required by the Mancini et al. (2002) approach, by generating a long series of synthetic precipitation, which is then coupled to a continuous time Explicit Soil Moisture Accounting (ESMA) rainfall-runoff model. The use of continuous simulation, which necessarily implies continuous hydrological models of the ESMA type, was also advocated by Bras et al. (1985); Beven (1987); Cameron et al. (1999), and seems the most appropriate way for determining the statistical dependence of the rainfallrunoff relation to the initial soil moisture conditions. The statistical analysis of the long series of synthetic results allows in development of joint and conditional probability functions, which are then used within a Bayesian context to determine the appropriate rainfall thresholds.

As presently implemented, the approach does not take into account the uncertainty in the quantitative precipitation forecasts $(\mathrm{QPF})$ provided by the numerical weather prediction (NWP) models. However, since the uncertainty of QPF is still quite substantial, an extension of the present approach is under development to incorporate this uncertainty by means of a Bayesian technique. Nonetheless, this first step was felt essential to demonstrate the feasibility of the proposed technique with respect to the simple unconditional rainfall thresholds, i.e. independent from the initial soil moisture condi- tions, which today are the basis for issuing warnings in many countries.

\section{Description of the proposed methodology}

In order to simplify the description of the methodology, two phases are here distinguished: (1) the rainfall thresholds estimation phase and (2) the operational utilization phase. The first phase includes all the procedures aimed at estimating the rainfall thresholds related to the risk of exceeding a critical water stage (or discharge) value at a river section. These procedures are executed just once for each river section of interest as well as for each forecasting horizon. The second phase includes all the operations to be carried out each time a significant storm is foreseen, in order to compare the precipitation volume forecast by a meteorological model with the critical threshold value already determined in phase 1 .

\subsection{The rainfall thresholds estimation}

As presented in Sect. 1.2, rainfall thresholds are here defined as the cumulated volume of rainfall during a storm event which can generate a critical water stage (or discharge) at a specific river section. When the rainfall threshold value is exceeded, the likelihood that the critical river level (or discharge) will be reached is high and consequently it becomes appropriate to issue a flood alert; alternatively, no flood alert is going to be issued when the threshold level is not reached. In other words the rainfall thresholds must incorporate a "convenient" dependence between the cumulated rainfall volume during the storm duration and the possible consequences on the water level or discharge in a river section. The term "convenient" is here used according to the meaning of the decision theory under uncertainty conditions, namely the decision which corresponds to the minimum (or the maximum) expected value of a Bayesian cost utility function.

Given the different initial soil moisture conditions, which can heavily modify the runoff generation in a catchment, it is necessary to clarify that it is not possible to determine a unique rainfall threshold for a given river section. It is well known that the water content in the soil strongly affects the basin hydrologic response to a given storm, with the consequence that a storm event considered irrelevant in a dry season, can be extremely dangerous in a wet season when the extent of saturated areas may be large. This implies the necessity of determining several rainfall thresholds for different soil moisture conditions. Although one could define a large number of them, for the sake of simplicity and applicability of the method, similar to what is done in the Curve Number approach (Hawkins, 1985), only three classes of soil moisture condition have been considered in this work: dry soil, moderately saturated soil, wet soil. A useful indicator for discriminating among soil moisture classes, the An- 


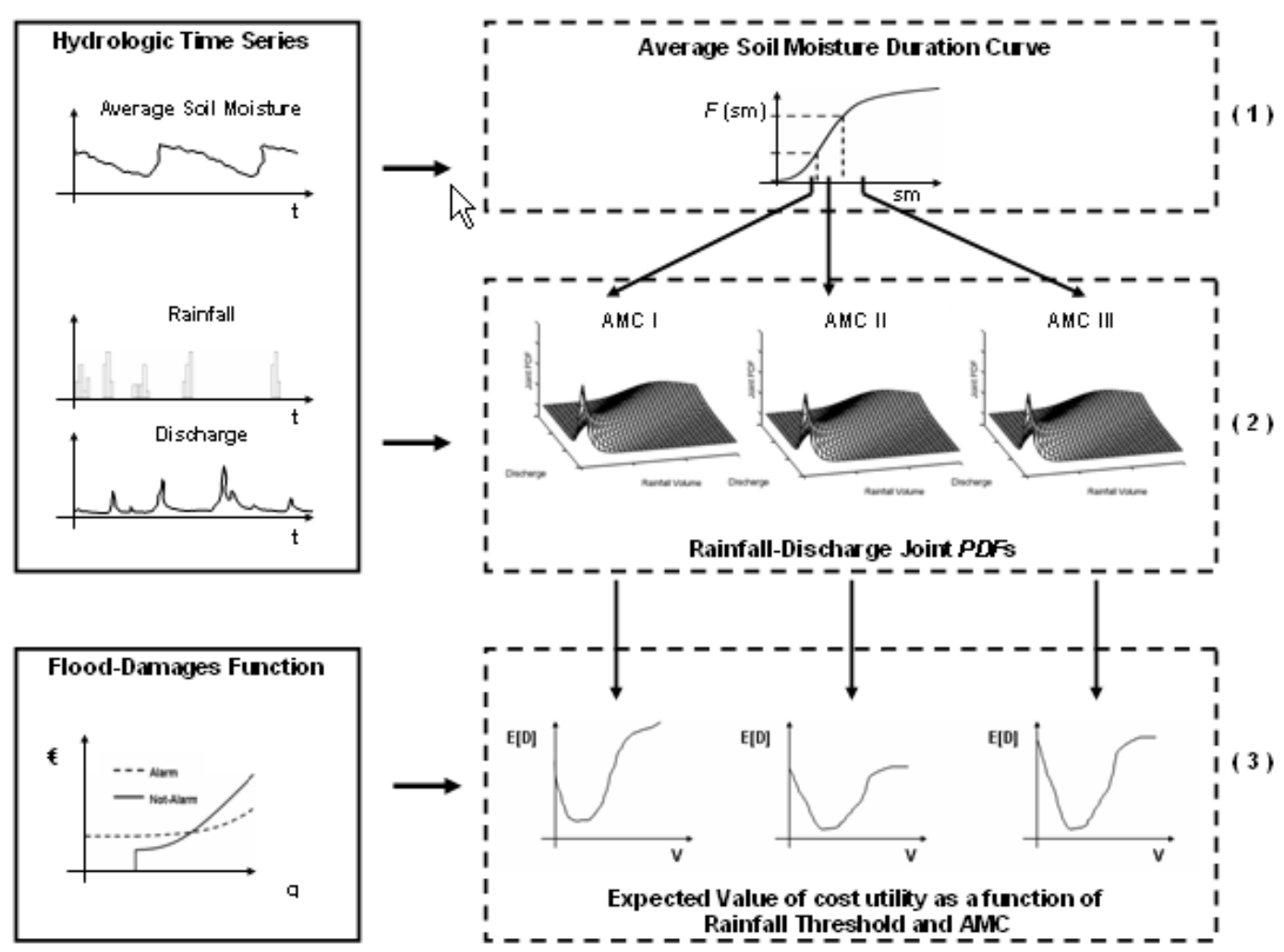

Fig. 2. Schematic representation of the proposed methodology. (1) Subdivision of the three synthetic time series according to the soil moisture conditions (AMC); (2) Estimation of the joint pdfs between rainfall volume and water stage or discharge; (3) Estimation of the "convenient" rainfall threshold based on the minimisation of the expected value of the associated utility function.

tecedent Moisture Condition (AMC) can be found in the literature (Gray, 1982; Hawkins, 1985), which leads to the following three classes of soil moisture AMC I (dry soil), AMC II (moderately saturated soil) and AMC III (wet soil). Since each AMC class will condition the magnitude of the rainfall threshold, three threshold values have to be determined.

Given the loose link that can be found between rainfall totals and the corresponding water stages (or discharges) at a given river section, the estimation of the rainfall thresholds requires the derivation of the joint probability function of rainfall totals over the contributing area and water stages (or discharges) at the relevant river section. This derivation is based on the analysis of three continuous time series: (i) the precipitation averaged over the catchment area, (ii) the mean soil moisture value, (iii) the river stage (or the discharge) in the target river section. It is obvious that these time series must be sufficiently long (possibly more than 10 years) to obtain statistically meaningful results. In the more usual case when the historical time series are not long enough, the average rainfall over the catchment is simulated by a stochastic rainfall generation model whose parameters are estimated on the basis of the observed historical time series. The rainfall stochastic model adopted in this work is the Neyman-Scott Rectangular Pulse NSRP model, widely documented in the literature (Rodriguez-Iturbe et al., 1987a; Cowpertwait et al., 1996). With the above mentioned model, 10000 years of hourly average rainfall over the catchment were generated and used as the forcing of a hydrologic model. The model used in this work is the lumped version of TOPKAPI (Todini and Ciarapica, 2002; Ciarapica and Todini, 2002; Liu and Todini, 2002). described in Appendix A with which the corresponding 10000 years of hourly discharges and soil moisture conditions have been generated.

At this point it is worthwhile noting that:

- The choice of the stochastic rainfall generation model and the rainfall-runoff model is absolutely arbitrary and does not affect the generality of the proposed methodology.

- Only the average areal rainfall on the basin is used in the proposed approach thus neglecting the influence of its spatial distribution. Therefore, the suitable range for applying the proposed methodology is limited to small and medium size basins (roughly up to 1000$2000 \mathrm{~km}^{2}$ ), where the extension of the forecasting lead time by means of QPF may be of great interest for operational purposes, also taking into account that the QPF 


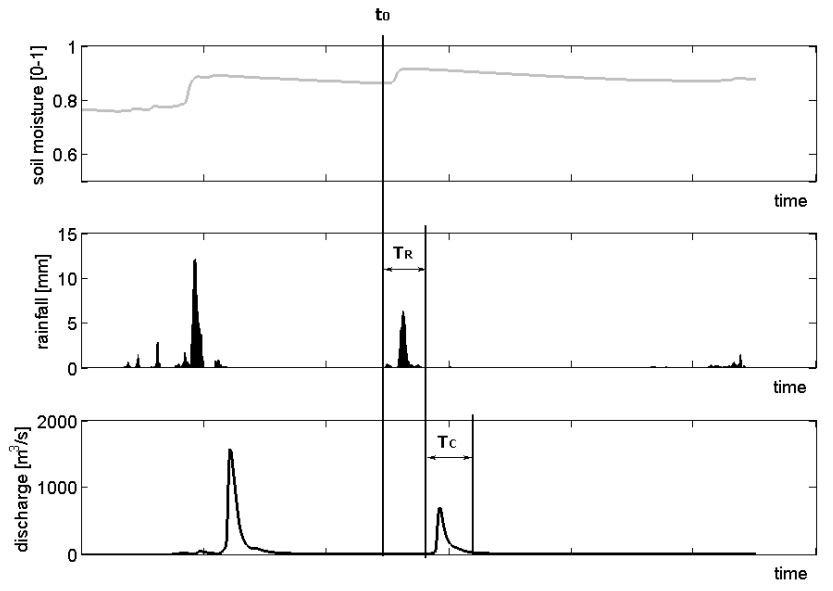

Fig. 3. The synthetic time series and the three time values used in the analysis: $t_{0}$ is the time of the storm arrival, $T$ is the time interval for the rainfall accumulation, $T_{C}$ is the time of concentration for the catchment.

is generated by the meteorological models with a rather coarse resolution (generally larger than $7 \times 7 \mathrm{~km}^{2}$ ).

- The results obtained via simulation are not the threshold values, but less stringent relations such as: (1) indicators incorporating the information on the mean soil moisture content, which are used to discriminate the appropriate AMC class and (2) the joint probability density functions between total rainfall over the catchment and the water stage (or discharge) at the river section of interest.

Phase 1 of the proposed methodology for deriving the rainfall thresholds follows the three steps illustrated in Fig. 2:

Step 1. Subdivision of the three time series obtained via simulation (generated average rainfall, simulated average soil moisture content, simulated water stage or discharge at the outlet) according to the defined soil moisture conditions (AMC) (Sect. 2.2);

Step 2. Estimation, for each of the identified AMC classes, of the joint probability density function of the rainfall cumulated over the forecasting horizon(s) of interest and the maximum discharge in a related time interval (Sect. 2.3);

Step 3. Estimation of a rainfall alarm threshold, for each of the identified AMC classes (Sect. 2.4).

2.2 Step 1: Sorting the time series according to the AMC classes

In order to account for the different soil moisture initial conditions, it is necessary to divide the three synthetic records, namely the stochastically generated rainfall, the soil moisture conditions and the water levels (or discharges) obtained via simulation, in three subsets, each corresponding to a different AMC class.

This subdivision is performed on the basis of the AMC value relevant to the soil moisture condition preceding a

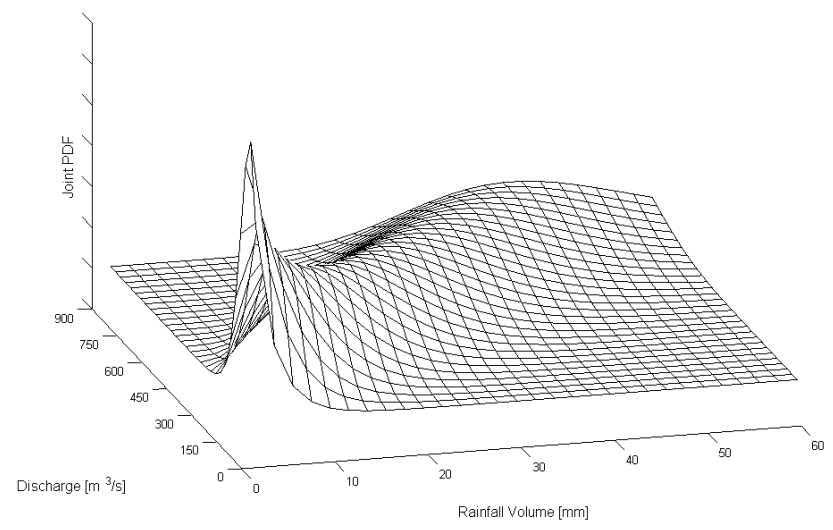

Fig. 4. A typical joint probability density function for rainfall volume and discharge with different (exponential and log-normal) marginal densities for a given soil moisture AMC class.

storm event. According to this value, the corresponding rainfall and discharge time series will be grouped in the appropriate AMC classes. This operation needs some further clarification, since the search for the rainfall totals and the corresponding discharge (or water stage) must each be done in different time intervals in order to account for the catchment concentration time.

With reference to Fig. 3, three time values are defined:

$t_{0} \quad$ the storm starting time

$T$ the rainfall accumulation time

$T_{C}$ the catchment concentration time

$T_{C} \quad$ can be estimated from empirical relationships based on the basin geomorphology or from time series analysis, when long records are available. As it emerged from the sensitivity analysis of the proposed methodology, in reality there is no need of great accuracy in the determination of $T_{C}$.

On the basis of the above defined time values, the rainfall volume $V_{T}$ (or rainfall depth) accumulated from $t_{0}$ to $t_{0}+T$ and the maximum discharge value $Q$ (or the maximum water stage) occurring in the time interval from $t_{0}$ to $t_{0}+T+T_{C}$ are retained and grouped in one of the classes according to the AMC value at $t_{0}$.

For a better description of the probability densities, although not essential, it was decided to construct the AMC classes so that they would each incorporate approximately the same number of joint observations. Therefore, the soil moisture contents corresponding to the 0.33 and 0.66 percentiles can be used to discriminate among the three classes. Accordingly, based on the initial soil moisture condition at $t_{0}$, the different events are classified as AMC I (dry soil), AMC II (moderately saturated soil ) and AMC III (wet soil). It is evident that this convenient class labelling has a different meaning from the SCS method with which should not be confused. 


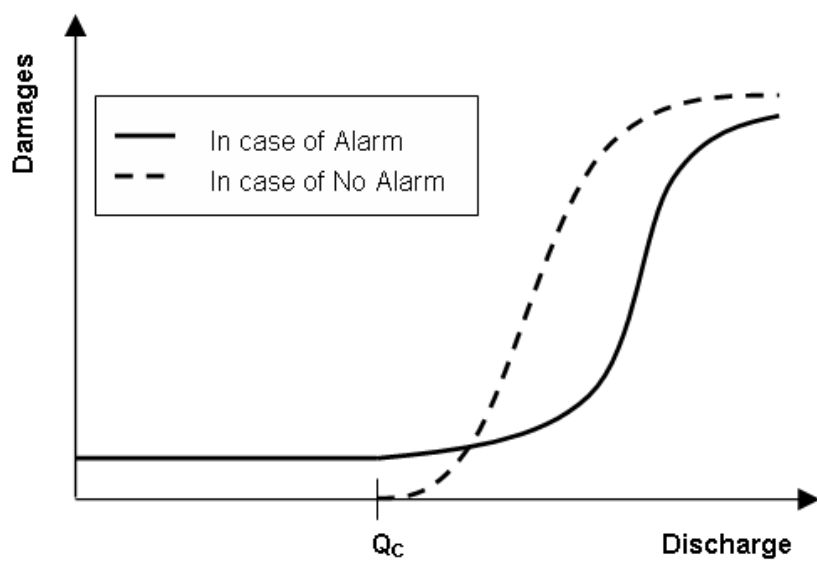

Fig. 5. Cost utility functions used to express the stakeholder perceptions.

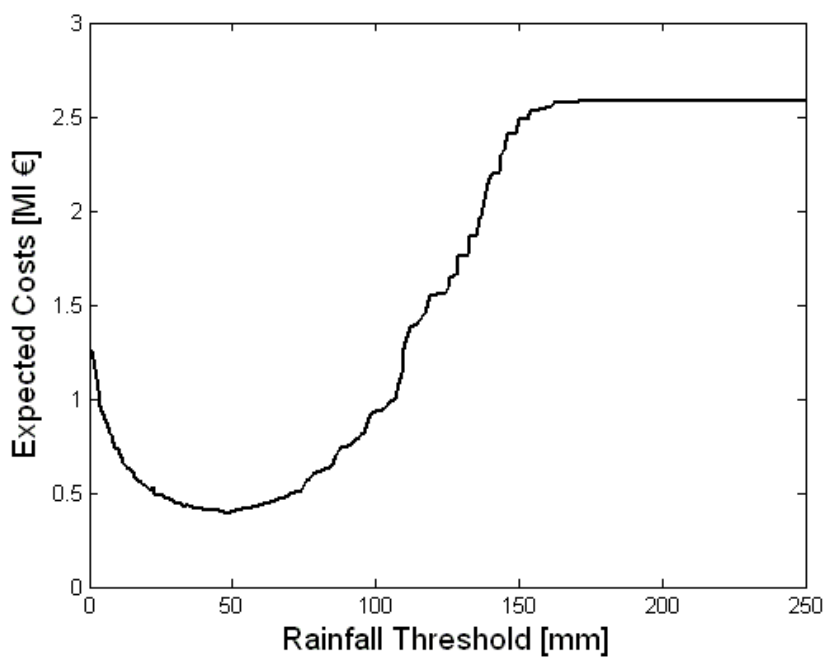

Fig. 6. Expected value of the cost utility as a function of different rainfall threshold values. This analysis is repeated for each time rainfall accumulation time $\mathrm{T}$ and for each Antecedent Soil Moisture conditions class. For instance this graph is referred to AMC II and $\mathrm{T}=12 \mathrm{~h}$.

\subsection{Step 2: Fitting the joint probability density function}

Once the corresponding pairs of values (the rainfall total and the relevant maximum water stage or discharge) have been sorted into the three AMC classes, for each class one can use these values to determine the joint probability density functions (jpdf) between the rainfall total and the relevant maximum discharge (or the water stage), to be used in step three. A jpdf will be estimated for each different forecasting horizon $T$, which will coincide with the rainfall accumulation time.

The problem of fitting a bi-variate density $f(q, v \mid T)$ in which marginal densities are vastly different (quasi lognormal for that of discharges and quasi exponential in terms

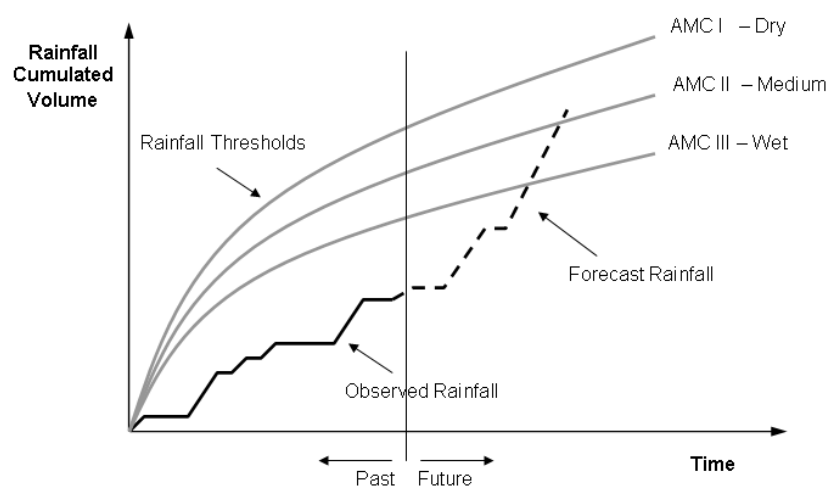

Fig. 7. Example of the rainfall thresholds derived for each AMC class as a function of rainfall accumulation time: when the soil is wet the threshold will obviously be lower.

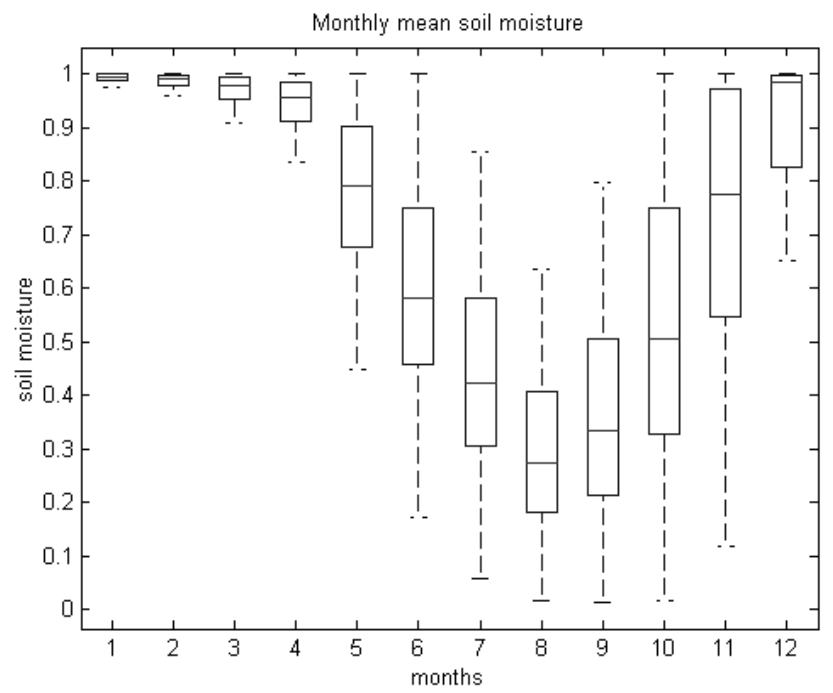

Fig. 8. Box plot of the mean monthly soil moisture condition calculated using the TOPKAPI model for the Sieve catchment.

of rainfall totals) can be overcome either by using a "copula" (Nelsen, 1999) or more interesting a Normal Quantile Transform (NQT) (Van der Waerten, 1952, 1953; Kelly and Krzysztofowicz, 1997). Figure 4 shows an example of the shape of one of the resulting bi-variate densities.

\subsection{Step 3: Estimation of the most convenient rainfall threshold}

The concept of flood warning thresholds takes its origins from the flood emergency management of large rivers, where the travel time is longer than the time required to implement the planned protection measures. In this case, the measurement of water stages at an upstream cross section can give accurate indications of what will happen at a downstream section in the following hours. Therefore, critical threshold levels were established in the past on the basis of water stage 

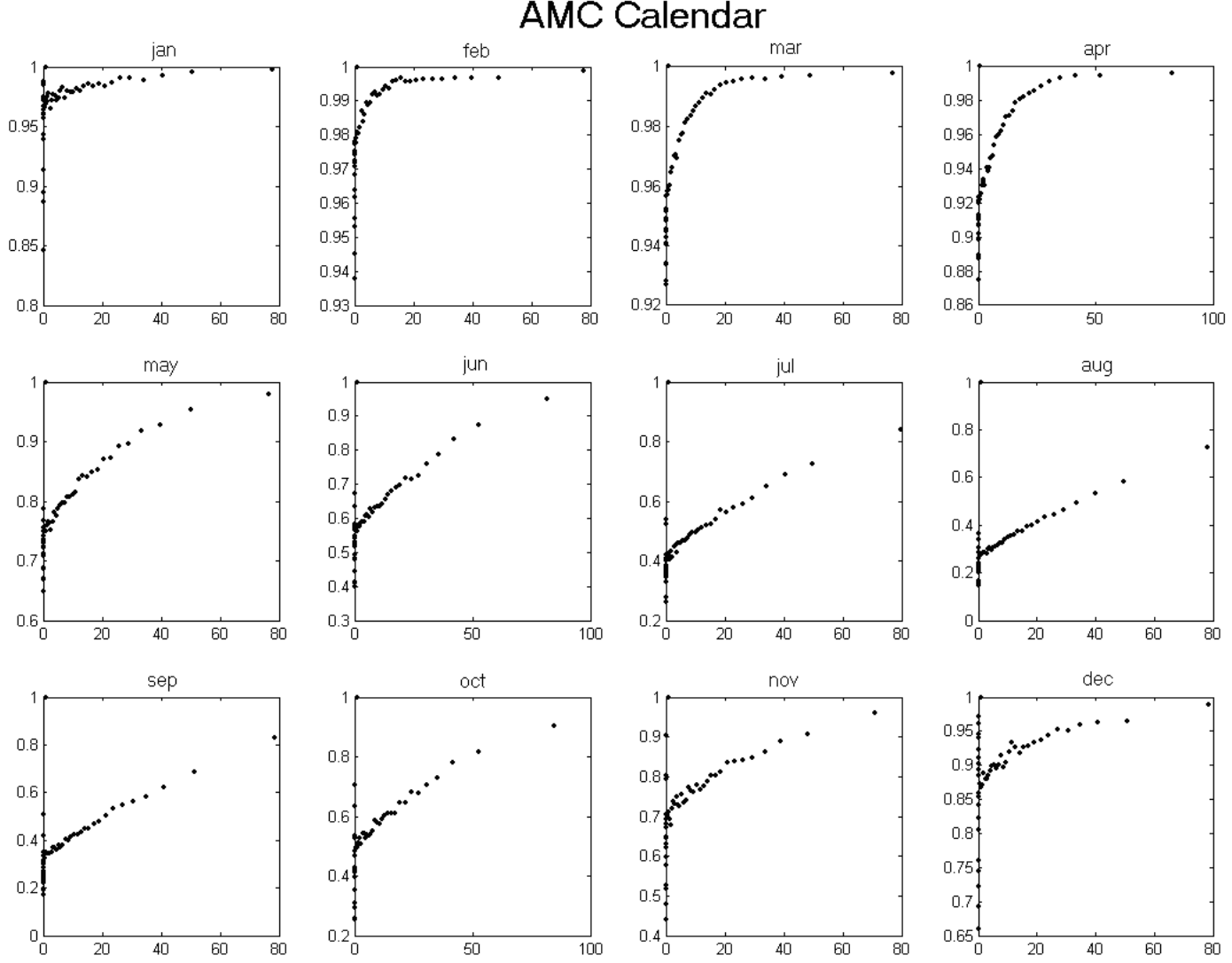

Fig. 9. The AMC calendar for the antecedent soil moisture condition estimation.

measurements rather than on their forecasts. Unfortunately, when dealing with smaller catchments, the flood forecasting horizon is mostly limited by the concentration time of the basin, which means that one has to forecast the discharges and the river stages as a function of the measured or forecasted precipitation. In this case, uncertainty affects the forecasts and the problem of issuing an alert requires determining the expected value of some utility or loss function. In the present work, following Bayesian decision theory (Benjamin and Cornell, 1970; Berger, 1986), the concept of "convenience" is introduced as the minimum expected cost under uncertainty. The term "cost" does not refer to "actual costs" of flood damages that are probably impossible to be determined, but rather a Bayesian utility function describing the damage perception of the stakeholder, which may even include the non commensurable damages due to "missed alert".

Without loss of generality, in the present work the following cost function, graphically shown in Fig. 5, is expressed in terms of discharge:

$U\left(q, v \mid V_{T}, T\right)= \begin{cases}\frac{a}{1+b e^{-c\left(q-Q^{*}\right)}} & \text { when } v \leq V_{T} \text { and no alert is issued } \\ C_{0}+\frac{a^{\prime}}{1+b^{\prime} e^{-c^{\prime}\left(q-Q^{*}\right)}} & \text { when } v>V_{T} \text { and an alert is issued }\end{cases}$

with $T$ the time of rainfall depth accumulation, $v$ the fore- casted volume and $V_{T}$ the rainfall threshold value, while $a, b, c$ and $a^{\prime}, b^{\prime}, c^{\prime}$ are appropriate parameters. Due to the fact that the utility functions are only functional to the final objective of providing the decision makers with tools reflecting their risk perception, the shape of such functions, as well as the relevant parameter values, can be jointly assessed, by analysing the relevant effects on the decision process over past events.

$U\left(q, v \mid V_{T}, T\right)$ is the utility cost function, which if $v \leq V_{T}$ expresses the perception of damages when no alert is issued (the dashed line in Fig. 5): no costs will occur if the discharge $q$ will remain smaller than a critical value $Q^{*}$, while damage costs will grow noticeably if the critical value is overtopped. On the contrary, if $v_{i} V_{T}$ it expresses the perception of damages when the alert is issued (the solid line in Fig. 5) a cost which will be inevitably paid to issue the alert (evacuation costs, operational cost including personnel, machinery etc.), and damage costs growing less significantly when the critical value $Q^{*}$ is overtopped and the flood occurs. As can be seen from Fig. 5, the utility function to be used will differ depending on the value of the cumulated rainfall forecast $v$ and the rainfall threshold $V_{T}$. If the forecast precipitation value is smaller or equal to the threshold value, the alert will not be issued; on the contrary, if the forecasted precipitation value 
Table 1. AMC classes definition according to the SCS approach

\begin{tabular}{lcc}
\hline & 5-day antecedent rainfall totals $[\mathrm{mm}]$ \\
\hline AMC class & Dormant season & Growing season \\
\hline AMC I (dry) & $\mathrm{P}<12.7$ & $\mathrm{P}<35.6$ \\
AMC II (medium) & $12.7<\mathrm{P}<27.9$ & $35.6<\mathrm{P}<53.3$ \\
AMC III (wet) & $\mathrm{P}>27.9$ & $\mathrm{P}>53.3$ \\
\hline
\end{tabular}

is greater than the threshold value, an alarm will be issued.

The most "convenient" rainfall threshold value $V_{T}^{*}$ can thus be determined by search as the one that minimises the expected utility cost, namely:

$$
\begin{aligned}
V_{T}^{*} & =\operatorname{Min}_{V_{T}}\left\langle E\left\{U\left(q, v \mid V_{T}, T\right)\right\}\right\rangle \\
& =\operatorname{Min}_{V_{T}}\left\langle\int_{0}^{+\infty} \int_{0}^{+\infty} U\left(q, v \mid V_{T}, T\right) f(q, v \mid T) d q d v\right\rangle
\end{aligned}
$$

where $f(q, v \mid T)$ is the joint probability distribution function of the rainfall volume and the discharge peak value described in Sect. 2.3. One rainfall threshold value $V_{T}^{*}$ will be derived for each accumulation time $T$. In Figure 6 one can see the typical shape of the expected value of the utility $E\left\{U\left(q, v \mid V_{T}, T\right)\right\}$ for a given accumulation time $T$.

Finally, Fig. 7 shows that all the values of the rainfall thresholds obtained for each AMC class, can be plotted as a function of the rainfall accumulation time. In the same Fig. 7, one can also appreciate the simplicity of the procedure used to decide whether or not to issue an alert. It is sufficient to progressively accumulate the forecast rainfall totals, starting from the measured rainfall volume and to compare the value to the appropriate AMC threshold value.

\section{Operational use of the rainfall threshold approach}

In order to operationally use the rainfall thresholds approach, whenever a storm event is forecast, one has to identify the AMC class to be used and the relevant rainfall threshold. This can be done without running a hydrological model in real time. For instance, in the cited work by Mancini et al. (2002), the AMC is estimated according to the Soil Conservation Service definitions (SCS, 1986) reported in Table 1. However, the approach, although very simple, can lead to an incorrect estimation of the antecedent soil moisture, since it neglects the intra-annual long term dependency (seasonality) of the soil moisture conditions. As a matter of fact (see Table 1) the SCS AMC only incorporates the information relevant to the precipitation of the previous 5 days, while from the example of Fig. 8, where the box plot of the mean monthly soil moisture condition is displayed, one can notice that the intra-annual variability of the soil moisture can be very high and the short-term influence of the precipitation
Table 2. Two-by-two contingency table for the assessment of a threshold based forecasting system

\begin{tabular}{lccc}
\hline & \multicolumn{3}{c}{ Forecasts } \\
\hline Observations & Warning & No Warning & Total \\
& $W$ & $W^{\prime}$ & \\
\hline Event, $E$ & $h$ & $m$ & $e$ \\
Non Event, $E^{\prime}$ & $f$ & $c$ & $e^{\prime}$ \\
Total & $w$ & $w^{\prime}$ & $n$ \\
\hline
\end{tabular}

alone is not sufficiently informative to correctly estimate the antecedent soil moisture conditions.

Therefore, an alternative methodology, which makes use of the long synthetic time series, already obtained for the thresholds derivation, is here proposed, to be applied only once in phase 1. As one can see from Fig. 9, it is possible to determine on a monthly basis, the simulated mean soil moisture as a function of the cumulated rainfall volume over the previous $n$ days. More in detail, Fig. 9 shows for the Sieve catchment, on which the methodology was tested, the mean soil moisture of the month vs the precipitation volume cumulated over the previous $72 \mathrm{~h}$. These results were obtained by using the 10000 years synthetic rainfall and the corresponding simulated soil moisture series. The graphs in Fig. 9 will be referred to as the "AMC Calendar". There is an evident dependency of the soil saturation condition on the antecedent precipitation and it is quite easy to estimate the appropriate AMC class by means of the AMC Calendar by comparing the cumulated rainfall value with the 0.33 and 0.66 quantiles determined as described in Sect. 2.2 (Fig. 10).

When a storm is forecast, using the rainfall thresholds together with the AMC Calendar, it is possible to:

Determine the mean catchment soil moisture and the correct AMC class, by entering into to the monthly graph with the cumulated rainfall volume recorded in the previous $n \mathrm{~h}$;

Choose the rainfall threshold corresponding to the identified AMC class;

Add the forecast accumulated rainfall to the observed rainfall volume;

Issue a flood alert if the identified threshold is overtopped.

\section{A framework for testing the procedure}

Following the meteorological literature, a framework based on contingency tables was used to assess the performance of the proposed approach. Contingency tables are highly flexible methods that can be used to estimate the quality of a deterministic forecast system (Mason and Graham, 1999) and, in their simplest form, indicate its ability to anticipate correctly the occurrence or non occurrence of predefined events. A warning $W$ is defined as the forecast of the occurrence of an event $E$ (in this case the overtopping of a threshold). 


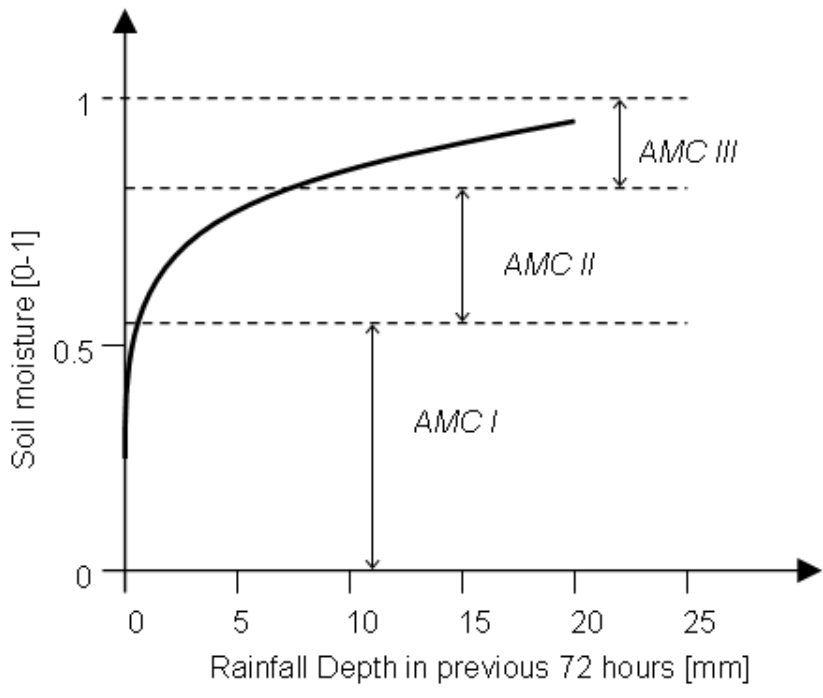

Fig. 10. The use of the monthly AMC Calendar to determine the appropriate AMC class.

A two-by-two contingency table can be constructed as illustrated in Table 2. From a total number of $n$ observations, one can distinguish the total number of event occurrences $(e)$ and that of non-occurrences $\left(e^{\prime}\right)$; the total number of warnings is denoted as $w$, and that of no-warnings as $w^{\prime}$. The following outcomes are possible: a hit, if an event occurred and a warning was issued (with $h$ the total number of hits); a false alarm, if an event did not occur but a warning was issued (with $f$ the total number of false alarms); a miss, if an event occurred but warning was not issued (with $m$ the total number of misses); a correct rejection, if an event did not occur and a warning was not issued (with $c$ the total number if correct rejections).

The skill of a forecasting system can be represented on the basis of the hit rate and the false-alarm rate. Both ratios can be easily evaluated from the contingency table (Mason, 1982):

$$
\left\{\begin{array}{l}
\text { hit rate }=\frac{h}{h+m}=\frac{h}{e} \\
\text { false-alarm rate }=\frac{f}{f+c}=\frac{f}{e^{\prime}}
\end{array}\right.
$$

The hit and false-alarm rates (Eq. 3), indicate respectively the proportion of events for which a warning was provided correctly, and the proportion of non events for which a warning was provided incorrectly. The hit rate is sometimes known as the probability of detection and provides an estimate of the probability that an event will be forewarned, while the false-alarm rate provides an estimate of the probability that a warning will be incorrectly issued (Eq. 4).

$$
\begin{cases}\text { hit rate } & =p(W \mid E) \\ \text { false-alarm rate } & =p\left(W \mid E^{\prime}\right)\end{cases}
$$

For a system that has no skill, warnings and events are by definition independent occurrences, therefore, the probabil-

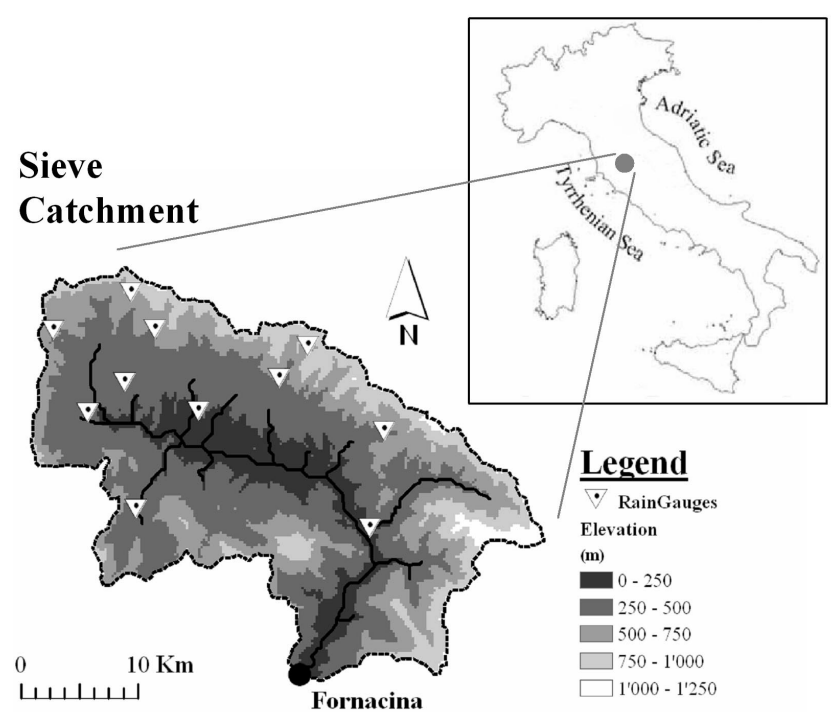

Fig. 11. The River Sieve catchment and the location of the different gauges.

ity of issuing an alert does not depend upon the occurrence or non occurrence of the event, namely:

$p(W \mid E)=p\left(W \mid E^{\prime}\right)=p(W)$

This equality occurs when warnings are issued at random. When the forecast system has some skill, the hit rate exceeds the false-alarm rate; a bad performance is indicated by falsealarm rate exceeding the hit rate. Because of the equality of the hit and false-alarm rates for all forecasts strategies with no skill, the difference between the two rate indexes can be considered an equitable skill score ss (Gandin and Murphy, 1992).

$s s=p(W \mid E)-p\left(W \mid E^{\prime}\right)$

\section{The case study}

The proposed methodology was applied to the case study of the River Sieve. The River Sieve is a predominantly mountain river, which flows into the River Arno just upstream of the city of Florence in Italy (Fig. 11). The catchment area is approximately $700 \mathrm{~km}^{2}$ at the river cross section at Fornacina with an elevation ranging form $300 \mathrm{~m}$ to $1300 \mathrm{~m}$. The climate is temperate and generally wet with extreme rainfall events in fall and spring which may cause flash floods. On 4 November 1966, one of the major floods of the Sieve, which highly contributed to the Florence flooding, was recorded, with more than $800 \mathrm{~m}^{3} \mathrm{~s}^{-1}$. For this study, rainfall and temperature hourly observations were available for 7 years at 12 measurement stations (11 raingauges 1 river stage + rating curve) located within the basin. A comprehensive database for soil textures, soil types and land use at the local scale 


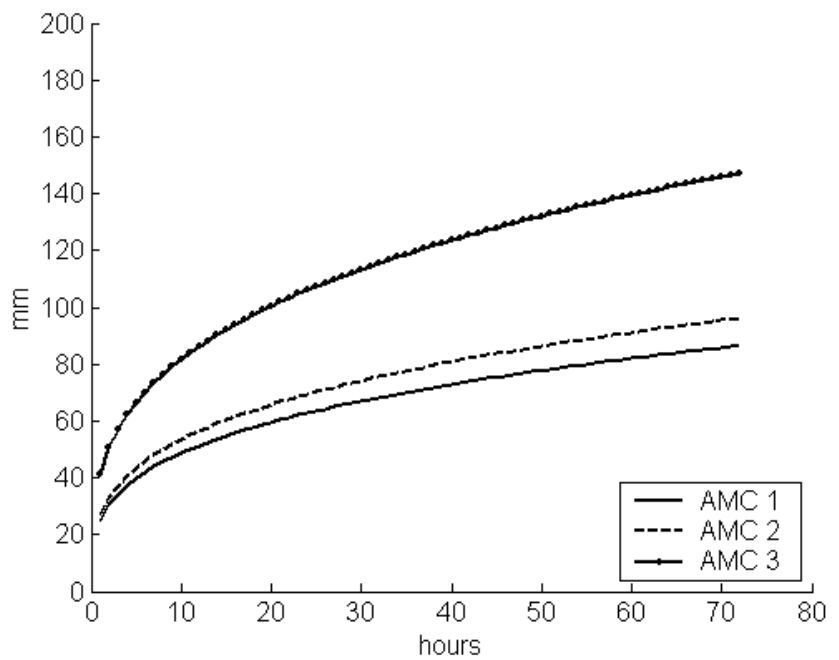

Fig. 12. The three rainfall thresholds derived for the Sieve at Fornacina.

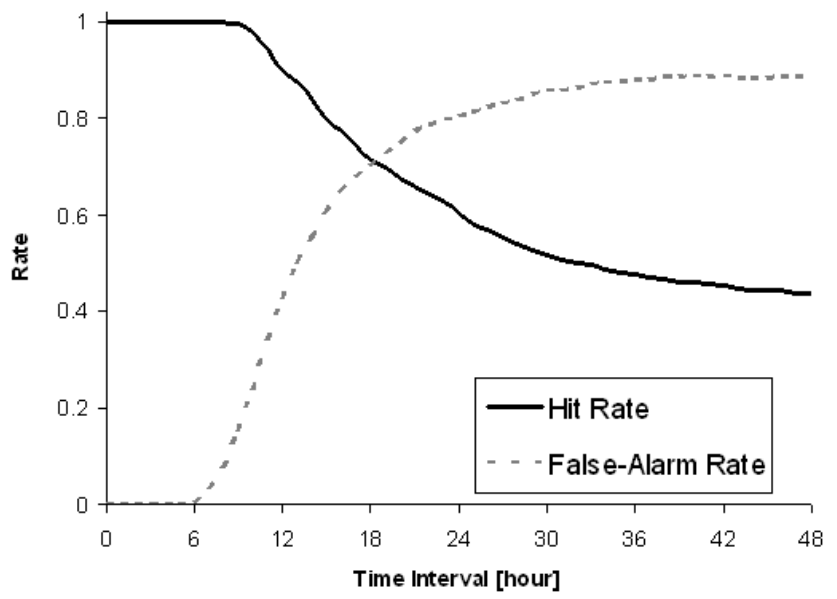

Fig. 13. Hit Rate and False-Alarm Rate as a function of flood forecasting horizon for the case of the River Sieve at Fornacina.

obtained from surveys carried out in the last 10 years was also available. The conversion from water levels to river discharges at the Fornacina cross section is obtained by means of a rating curve, derived on the basis of flow velocity measures and field surveys of the river cross section geometry, and provided by the Tuscany Regional Hydrological Service.

According to the proposed methodology, a series of 10000 years of hourly rainfall was generated by means of the Neyman-Scott Rectangular Pulse NSRP model (RodriguezIturbe et al., 1987a; Cowpertwait et al., 1996). The generated rainfall was then used as input to the lumped TOPKAPI, a hydrological model described in Appendix A. The rainfall as well as the resulting discharges series were divided in three subsets (AMC1, AMC2, AMC3) according to the time series of Antecedent Moisture Condition, also resulting from the hydrological simulation. "Convenient" rainfall threshold

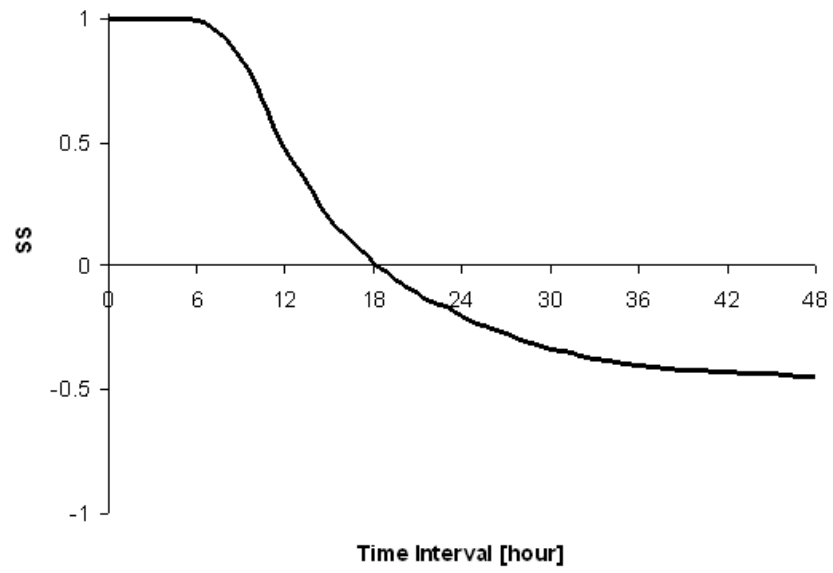

Fig. 14. Skill score as a function of flood forecasting horizon for the case of the River Sieve at Fornacina.

values were then found by means of Eq. 2 for an increasing time horizon $T$ ranging from 0 to $72 \mathrm{~h}$. Figure 12 shows the results obtained for the Sieve catchment at Fornacina.

The verification of the forecasting capabilities of the proposed methodology applied to the Sieve at Fornacina, based upon the validation framework described in Sect. 4, was performed by generating a 1000 year long time series of synthetic rainfall, different from the 10000 year one used for setting up the methodological approach. The cases of Correctly Issued Alarms $(h)$, Missed Alarms $(m)$, False Alarms $(f)$, Correctly Rejected Alarms $(c)$ were computed for different lead time horizons $T$. Based on the results, the hit rate and the false-alarm rate (Fig. 13) as well as the Skill Score (ss) (Fig. 14), were computed following their definitions given in Eq. 3 and Eq. 6 respectively as a function of accumulation time $T$.

From Fig. 13, it is interesting to notice that the false alarm rate stays to zero up to an horizon of $6 \mathrm{~h}$ in advance while the hit rate remains almost 1 up to $9 \mathrm{~h}$ in advance, at which time the false alarm rate is approximately 0.1 . The quality of the results is also confirmed in Fig. 14, which shows that the skill score remains close to 1 up to $6 \mathrm{~h}$ in advance, while dropping to 0.9 up to $9 \mathrm{~h}$ in advance. There are two important issues to discuss in these graphs (Figs. 13 and 14). The first is the high performance obtained for the first 6 to $8 \mathrm{~h}$. This can be explained by the high correlation existing in this relative small catchment between the rainfall volume and the peak of the discharge within a short time interval which somehow is justified by the Dunne hypothesis. The typical duration for rainfall events of high intensity for this area varies between 5 and $12 \mathrm{~h}$; this causes the contemporary overtopping of the rainfall and flood threshold. The second issue is the quick drop of the skill after $9 \mathrm{~h}$. After this time window, neglecting the time distribution of the rainfall intensity makes the previous correlation to decay rapidly. As a matter of fact the approach does not distinguish between short duration high 

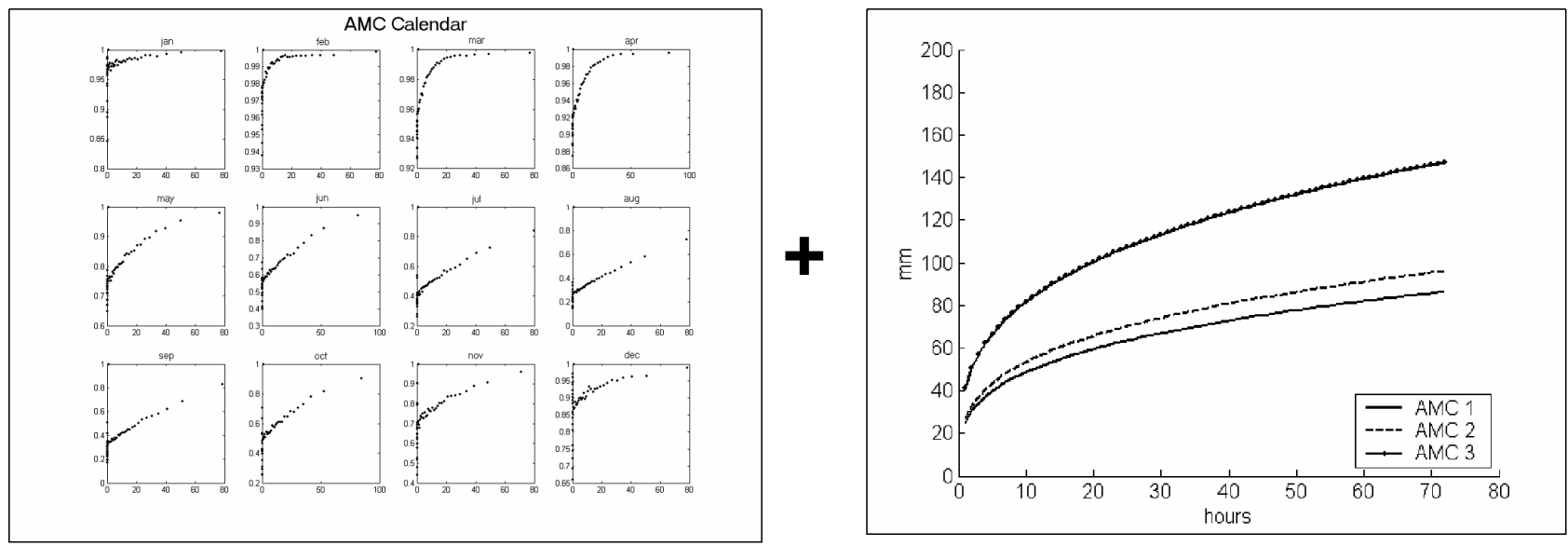

Fig. 15. The resulting two graphs on which the whole operational procedure of the proposed approach is based upon.

intensity events and long duration low intensity ones.

Moreover, it must be borne in mind that these results do not incorporate the "rainfall forecasting uncertainty". They were only derived, on the assumption of "perfect knowledge" of future rainfall, in order to validate the approach. In other words, the actually observed rainfall is here used as the "forecasted rainfall". In operational conditions, future rainfall is not known and only quantitative precipitation forecasts originated either by nowcasting techniques or by Limited Area Atmospheric models may be available.

The introduction of a probabilistic rainfall forecast will inevitably imply the derivation of an additional probability density $f(v \mid \hat{v})$, expressing the probability of observing a given rainfall volume $v$ conditional upon a forecasted volume $\hat{v}$, but it is envisaged that it will not completely modify the proposed procedure. Research work is currently under way to provide user oriented operational solutions and will be reported in a successive paper.

Nonetheless, it is worthwhile noting that the proposed methodology is very appealing for operational people. In fact, not only does it not require a flood forecasting model running in real time, but even a computer is not necessary in operational conditions: only the two graphs given in Fig. 15 are used in practice to evaluate the possibility of flooding. Therefore, the advantage of this method stems from its simplicity, thus providing a quick reference method to the stakeholders and the flood emergency managers interested at assessing, within a given lead time horizon, the possibility of flooding whenever a QPF is available.

\section{Conclusions}

This paper presented an original methodology aimed at issuing flood warnings on the basis of rainfall thresholds. The rainfall threshold values relevant to a given river cross section take into account the upstream catchment initial soil moisture conditions as well as the stakeholders' subjective perception on the convenience of issuing an alert, through the minimization of expected costs, within the framework of a Bayesian approach. The advantage of the proposed methodology lies in its extremely simple operational procedure, based solely on two graphs, that makes it easy to be understood and applied by non technical users, such as most flood emergency managers.

Nonetheless, not all the problems have been addressed for a successful operational use of the methodology. The procedure presented in this paper, although it can be considered as a great improvement from the presently used approaches, must be viewed as a first step towards a sound operational approach. The limitation of the present stage is due to the implicit assumption of "perfect knowledge" of future rainfall, in the sense that QPF is taken as a known quantity instead of an uncertain forecast. Although, this approach is currently used by most flood alert operational services, the role of the uncertainty in QPF has been presently brought to the attention of the community by meteorologists, through the use of ensemble forecasts and by meteorologists and hydrologists within the frame of the recently launched International Project HEPEX .

Ongoing research deals in fact with the problem of assessing uncertainty within the framework of the rainfall threshold approach.

The next step aims at incorporating the QPF uncertainty in the derivation of the rainfall thresholds, by taking the joint probability distribution function between rainfall and discharge (or water stage) derived via simulation as a distribution conditional on the knowledge of future rainfall. Given the probability density of future rainfall conditional on the QPF, it will then be possible to combine them in order to obtain the overall joint density from which one can integrate out the effect of the QPF uncertainty.

After that, an attempt will be made to assess the influence of the model (both rainfall simulator and hydrologic model) uncertainties on the rainfall threshold estimation, although 


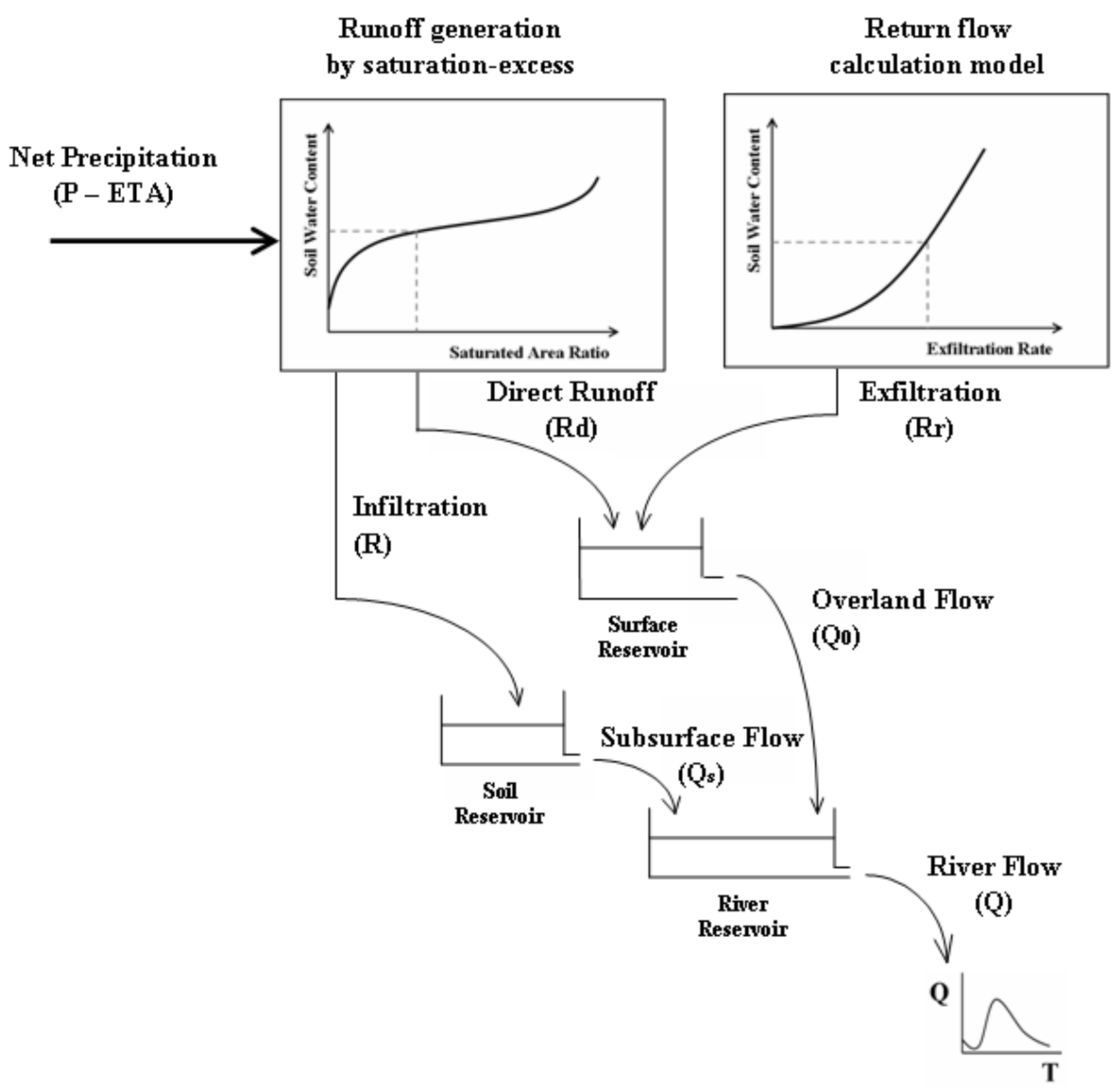

Fig. 16. The schematic representation of the lumped TOPKAPI hydrological model, according to Liu and Todini 20021.

the effect of this uncertainty is much smaller on decisions than the one produced by the large QPF uncertainty.

\section{Appendix A The rainfall-runoff model used: the lumped version of the TOPKAPI model}

Two of the hydrologic time series used in the proposed methodology (namely the soil moisture content and the discharge at the river section of interest) were generated by means of a lumped rainfall-runoff model (the lumped version of TOPKAPI), which allows for a continuous simulation at an hourly time step.

The TOPKAPI approach is a comprehensive distributedlumped approach widely documented in the literature (Todini and Ciarapica, 2002; Ciarapica and Todini, 2002; Liu and Todini, 2002). It was also shown (Liu and Todini, 2002), that the lumped TOPKAPI model schematized in Fig. 16, can be directly derived, without the need for a new calibration, from the distributed physically meaningful version. In the lumped version, a catchment is regarded as a dynamic system composed of three reservoirs: the soil reservoir, the surface reservoir and the channel reservoir. The precipitation on the catchment is partitioned into direct runoff and infiltration using a Beta-distribution curve, which reflects the non-linear relationship between the soil water storage and the saturated contributing area in the basin. The infiltration and direct runoff are then routed through the soil reservoir and surface reservoir, respectively. Outflows from the two reservoirs, namely interflow and overland flow, are then taken as inputs to the channel reservoir to form the channel flow.

As previously mentioned, it can be proven that the lumped version of the TOPKAPI model can be derived directly from the results of the distributed version and does not require additional calibration. In order to obtain the lumped version of the TOPKAPI, the point kinematic wave equation is firstly integrated over the single grid cell of the DEM (Digital Elevation Model) and successively the resulting non-linear storage equation is integrated over all the cells describing the basin. In the case of the soil model the following relation is obtained:

$$
\begin{aligned}
& \frac{\partial V_{S_{T}}}{\partial t}=R A-\left(\frac{\alpha_{s}+1}{\alpha_{S} X^{2}} \frac{1}{\sum_{1=1}^{N-1}\left(\prod_{m=\ell}^{N-1} f m\right)+1}\right)^{\alpha_{s}} \\
& X \bar{C}_{S_{T}} V_{S_{T}}^{a_{s}}=R A-b_{s} V_{S_{T}}
\end{aligned}
$$


with

$$
\begin{aligned}
\frac{1}{\bar{C}_{S_{T}}}= & \left\{\sum _ { i = 1 } ^ { N } \left\{\left[\frac{1+\sum^{j-1}\left(\prod_{m=\ell}^{j-1} f_{m}\right)}{\sum_{\ell}^{N-1}=1}\left(\prod_{m=\ell}^{N-1} f_{m}\right)=1\right]^{\frac{\alpha_{s}+1}{\alpha_{s}}}\right.\right. \\
& \left.-\left[\frac{\sum_{\ell=1}^{j-1}\left(\prod_{m=\ell}^{j-1}\right)}{\sum_{\ell=1}^{N=1}\left(\prod_{m=\ell}^{N-1} f_{m}\right)=1}\right]^{\frac{\alpha_{s}+1}{\alpha_{s}}}\right]_{C_{s_{i}}^{\frac{1}{\alpha_{s}}}}^{\alpha_{s}}
\end{aligned}
$$

where $i$ is the index of a generic cell; $j$ is the of cells drained by the $i^{t h}$ cell; $\mathrm{N}$ is the total number of cells in the upstream contributing area, $V_{S_{T}}$ is the water storage in the catchment, $R$ is the infiltration rate; $A$ is the catchment area; $f_{m}$ represents the fraction of the total outflow from the $m^{\text {th }}$ cell which flows towards the downstream cell, and $\alpha_{s}$ is a soil model parameter assumed constant in the catchment, $b_{s}$ is a lumped soil reservoir parameter which incorporates in an aggregate way the topography and physical properties of the soil.

Equation A1 corresponds to a non-linear reservoir model and represents the lumped dynamics of the water stored in the soil. The same type of equation can be written for overland flow and for the drainage network, thus transforming the distributed TOPKAPI model into a lumped model characterized by three "structurally similar" non-linear reservoirs, namely "soil reservoir", "surface reservoir" and "channel reservoir".

Due to the spatial variability of the different cells in terms of water storage and flow dynamics, the infiltration rate in Eq. A1 must be preliminarily evaluated by separating precipitation into direct runoff and infiltration into the soil. In order to obtain this separation, a relationship linking the extent of saturated areas and the volume stored in the catchment has to be introduced, similarly to what is done in the Xinanjiang model (Zhao, 1977), in the Probability Distributed Soil Capacity model (Moore and Clarke, 1981) and in the ARNO model (Todini, 1996).

Given the availability of a distributed TOPKAPI version, this relationship can be obtained by means of simulation. At each step in time the number of saturated cells is put in relation to the total volume of water stored in the soil over the entire catchment. Indicating with $V s_{T}$ the total water storage in the soil, with $V s s$ the soil water storage at saturation and with $A_{s}$ the total saturated area, the relationship between the extent of saturated areas and the volume stored in the catchment can be approximated by a Beta-distribution function curve expressed by Eq. A3:

$$
\frac{A_{s}}{A}=\int_{0}^{\frac{V_{S_{T}}}{V_{S S}}} \frac{\Gamma(r+s)}{\Gamma(r) \Gamma(s)} \varphi^{r-1}(1-\varphi)^{s-1} d \varphi
$$

with $\Gamma(x)$ the Gamma function defined as:

$\Gamma(x)=\int_{0}^{+\infty} \zeta^{x-1} e^{-\zeta} d \zeta \quad, x>0$

As it was found in the analysis of the distributed TOPKAPI results, an exfiltration phenomenon exists. For instance when rainfall stops and the relevant overland flow has receded, surface runoff can still be larger that the possible maximum interflow due to a return flow caused by exfiltration. This return flow is estimated using a limiting parabolic curve (Fig. 16) representing the relationship between the return flow and the fraction of saturation in the catchment, which parameters are estimated on the basis of the distributed TOPKAPI model simulation results. This parabolic curve can be expressed as equation:

$Q_{\text {return }}=\alpha_{1}\left(\frac{\bar{V} s_{T}}{V s s}\right)^{2}+a_{2} \frac{\overline{V s_{T}}}{V s s}+\alpha_{3}$

where $Q_{\text {return }}$ is the calculated return flow discharge during a time interval $t_{2}-t_{1}, \bar{V} s_{T}=0.5 C V s_{T_{1}}+V s_{T_{2}}$ is the averaged soil water storage, $a_{1}, a_{2}$ and $a_{3}$ are the parameters. Accordingly, the infiltration rate into the soil within the time interval $\Delta t$ can be computed by using equation:

$R=\frac{1}{A}\left(\frac{V_{S_{t_{2}}}-V_{S_{t_{1}}}}{t_{2}-t_{1}}-Q_{\mathrm{ret}}\right)$

The quantities $R$ and $R_{d}$ are then input into the soil reservoir and the surface reservoir, respectively. The interflow and the overland flow can be obtained by means of water balance method, and are then together drained into the channel reservoir to generate the total outflow at the basin outlet (Fig. 16).

For a more detailed description of the model refer to Liu and Todini, 2002.

Acknowledgements. The work described in this publication was supported by the European Community's Sixth Framework Programme through the grant to the budget of the Integrated Project FLOODsite, Contract GOCE-CT-2004-505420. This paper reflects the authors' views and not those of the European Community. Neither the European Community nor any member of the FLOODsite Consortium is liable for any use of the information in this paper.

Edited by: G. Pegram

\section{References}

Annunziati A., Focardi A., Focardi P., Martello S., and Vannocci P.: Analysis of the rainfall thresholds that induced debris flows in the area of Apuan Alps - Tuscany, Italy, Plinius Conference '99: Mediterranean Storms, Ed. Bios., 485-493, 1999.

Benjamin, J. R. and Cornell C. A.: Probability, Statistics, and Decision For Civil Engineers, McGraw-Hill, New York, 1970.

Berger, J. O.: Statistical Decision Theory and Bayesian Analysis, New York: Springer-Verlag, 1986. 
Beven, K.: Towards the use of catchment geomorphology in flood frequency predictions, Earth Surf. Processes Landforms, 12, 682, 1987.

Bras, R. L., Gaboury D. R, Grossman D. S and Vicen G. J.: Spatially varying rainfall and flood risk analysis, J. Hydraul. Eng., 111, 754-773, 1985.

Cameron, D. S., K. J. Beven, J. Tawn, S. Blazkova, and P. Naden: Flood frequency estimation by continuous simulation for a gauged upland catchment (with uncertainty), J. Hydrol., 219, 169-187, 1999.

Carpenter, T. M., Sperfslage J. A., Georgakakos K. P., Sweeney T., and Fread D. L.: National threshold runoff estimation utilizing GIS in support of operational flash flood warning systems, J. Hydrol., 224, 21-44, 1999.

Ciarapica L. and Todini E.: TOPKAPI: a model for the representation of the rainfall-runoff process at different scales, Hydrol. Processes, 16(2), 207-229, 2002.

Cowpertwait P. S. P.: Further developments of the Neyman-Scott clustered point processes for modelling rainfall, Water Resour. Res., 27(7), 1431-1438, 1991.

Cowpertwait P. S. P., O'Connell P. E., Metcalfe A. V., and Mawdsley J. A.: Stochastic point process modelling of rainfall, I. Single site fitting and validation, J. Hydrol., 175, 17-46, 1996.

Crosta, G. B. and Frattini P.: Rainfall thresholds for soil slip and debris flow triggering, Proceedings of the EGS 2nd Plinius Conference on Mediterranean Storms, Ed. Bios, 2000.

Crosta, G. B. and Frattini P.: Coupling empirical and physically based rainfall thresholds for shallow landslides forecasting, Proceedings of the EGS 3rd Plinius Conference on Mediterranean Storms, Ed. Bios, 2001.

Crosta, G. B. and Frattini P.: Distributed modelling of shallow landslides triggered by intense rainfall, Nat. Hazards Earth Syst. Sci., 3, 81-93, 2003.

EFFS: edited by: Gouweleeuw, B., Reggiani P., and de Roo, A., A European Flood Forecasting System, Full Report (Contract no. EVG1-CT-1999-00011, http://effs.wldelft.nl., 2004.

De Vita, P. and Reichenbach, P.: Rainfall triggered landslides: a reference list, Environ. Geol., 35(2/3), 219-233, 1998.

Gandin, L. S. and Murphy, A. H.: Equitable skill scores for categorical forecasts, Mon. Wea. Rev., 120, 361-370, 1992.

Georgakakos K. P.: Analytical results for operational flash flood guidance, J. Hydrol., in press, 317, 81-103, 2006.

Gray, D. D., Katz, P. G., deMonsabert, S. M., and Cogo, N. P.: Antecedent moisture condition probabilities, J. Irrig. and Drain. Engrg. Div., ASCE, 108(2), 107-114, 1982.

Hawkins, R. H., Hjelmfelt, A. T., and Zevenberger, A. W.: Runoff probability, storm depth, and curve numbers, J. Irrig. and Drain. Engrg., ASCE, 111(4), 330-340, 1985.

Hennrich, K.: Modelling Critical Water Contents for Slope Stability and Associated Rainfall Thresholds using Computer Simulations, in: Landslides in Research, Theory and Practice edited by: Bromhead, E., Dixon, N., and Ibsen, M.-L.: Proceedings of the 8th International Symposium on Landslides, Cardiff/UK, Thomas Telford Ltd, 2000.

Iverson, R.M.: Landslide triggering by rain infiltration, Water Resour. Res., 36(7), 1897-1910, 2000.

Joe H.: Parametric families of multivariate distributions with given margins, J. Multivar. Anal., 46, 262-282, 1993.

Joe, H., Multivariate Models and Dependence Concepts, Chapman
\& Hall, London, 1997

Kelly, K. S. and Krzysztofowicz, R.: A bivariate meta-Gaussian density for use in Hydrology, Stochastic Hydrology and Hydraulics, 11, 17-31, 1997.

Lamb R. and Kay A. L.: Confidence intervals for a spatially generalized, continuous simulation flood frequency model for Great Britain, Water Resour. Res., 40, W07501, doi:10.1029/2003WR002428, 2004.

Liu Z. and Todini E.: Towards a comprehensive physically-based rainfall-runoff model, Hydrol. Earth Syst. Sci., 6, 859-881, 2002.

Mancini M., Mazzetti P., Nativi S., Rabuffetti D., Ravazzani G., Amadio P., and Rosso R.: Definizione di soglie pluviometriche di piena per la realizzazione di un sistema di allertamento in tempo reale per il bacino dell'Arno a monte di Firenze, Proc. XXVII Convegno di idraulica e Costruzione Idrauliche, Volume, 2, 497505, Italy, 2002.

Mason, S. J.: A model for assessment of weather forecasts, Aust. Meteor. Mag., 30, 291-303, 1982.

Mason, S. J. and Graham, N. E.: Conditional Probabilities, Relative Operating Characteristics and Relative Operating Levels, Weat. Forecast., 14, 713-725, 1999.

Moore R. J. and Clarke R. T.: A distribution function approach to rainfall runoff modelling, Water Resour. Res., 17(5), 1367-1382, 1981.

Neary, D. G. and Swift L. W.: Rainfall thresholds for triggering a debris flow avalanching event in the southern Appalachian Mountains, Rew. Eng. Geol., 7, 81-95, 1987.

Nelsen, R. B.: An Introduction to Copulas, Springer-Verlag, New York, 1999.

Reed S., Johnson D., and Sweeney T.: Application and national Geographic Information System database to support two-year flood and threshold runoff estimates, J. Hydrol. Eng., 7, 3, 1 May , 209-219, 2002.

Rodriguez-Iturbe I., Cox D. R., and Isham V.: Some models for rainfall based on stochastic point processes, Proc. R. Soc. London, Ser. A, 410, 269-288, 1987a.

Rodriguez-Iturbe I., Febres De Power B., and Valdes J. B.: Rectangular Pulses point processes models for rainfall: analysis of empirical data, J. Geophys. Res., 92(D8), 9645-9656, 1987 b.

SCS - Soil Conservation Service: National Engineering Handbook, sect. 4, Hydrology, Rev. Ed., U.S.D.A., Washington D.C., USA, 1986.

Sweeney, T. L.: Modernized areal flash flood guidance. NOAA Technical Report NWS HYDRO 44, Hydrologic Research Laboratory, National Weather Service, NOAA, Silver Spring, MD, October, 21 pp. and an appendix, 1992.

Todini E.: The ARNO rainfall-runoff model, J. Hydrol. ,175, 339382, 1996.

Todini E. and Ciarapica L.: The TOPKAPI model. In Mathematical Models of Large Watershed Hydrology edited by: Singh, V. P., Frevert, D. K., and Meyer, S. P., Water Resources Publications, Littleton, Colorado, Chapter 12, 471-506, 2002.

Van der Waerden, B. L.: Order tests for two-sample problem and their power, Indagationes Mathematicae, 14, 253-458, 1952.

Wang, C. T., Gupta, V. K., and Waymire, E.: A geomorphologic synthesis of nonlinearity in surface runoff, Water Resour. Res., 17(3), 545-554, 1981.

Zhao R. J.: Flood forecasting method for humid regions of China, East China College of Hydraulic Engineering, Nanjing, 1977. 